\title{
TOXIC PROPERTIES OF PLASTICS IN FIRE AND THEIR IMPACT ON THE ENVIRONMENT AND HUMAN HEALTH
}

The article describes and analyses toxic substances produced during a combustion of plastics which affect human health. Accidents and emergencies resulting from the combustion of plastic materials occur very often during the industrial production and technological processes. The authors illustrate this fact using the most recent example - the fire in the manufacturing and logistics premises in Chropyne, the Czech Republic, during which the professional as well as volunteer firefighters and the specialized fire rescue service units were employed.

Key words: toxicity, fire, safety and fire protection.

\section{Introduction}

In the environment, in industry, motorism, aviation and in many other key industries a wide range of substances with various chemical properties is used. These, as a result of a chemical reaction caused by the fire, are transformed into tens or hundreds of different chemical substances with new and in most cases even more dangerous chemical properties. It is to be noted that the toxic properties of the newly produced substances depend also on the type of extinguishing agent used. Saving human lives (including the firefighters and other personnel) is the main goal during firefighting. The dangerous factors during firefighting are:

- elevated ambient temperature,

- excessive formation of smoke,

- decrease in oxygen content in the air and

- toxic products of fire.

Elevated ambient temperature makes the firefighters" work difficult, provokes defatigation and dehydration. Inhalation of hot products of combustion damages the airways, decreases blood pressure and may result in failure of blood circulation, pulmonary edema or even in death. Formation of smoke reduces visibility in the seat of fire and decreases the sense of orientation, mostly in an unknown area, but also in a familiar area. A smoke is in fact an aerosol, in which the dispersed phase is formed by carbon, dust or tar particles and other products of combustion. Highly toxic substances often condensate on the surfaces of the dispersed particles. Nowadays, it is widely known that smoke inhalation or contact of smoke with the skin represent a big danger. A conflagration needs oxygen in order to burn. Sometimes, oxygen is contained in the molecules of a combustible matter, but in most cases, it comes from the air. $23 \%$ of the weight of the air (and $21 \%$ of its volume) is made up of oxygen. It is the same amount which a human being needs to survive. During a fire, particularly in enclosed places, the amount of oxygen in the air decreases, which affects the performance of the firefighters and the lives of other people present in the seat of fire. The influence of the amount of oxygen in the air on human body is depicted in Table 1.

The influence of the amount of oxygen

Table 1. in the air on human body [5].

\begin{tabular}{|c|c|}
\hline $\begin{array}{c}\text { The amount of } \\
\text { oxygen in the air } \\
{[\%]}\end{array}$ & $\begin{array}{c}\text { Symptoms of } \\
\text { a lack of oxygen }\end{array}$ \\
\hline 21 & Normal course of life, no difficulties. \\
\hline 17 & $\begin{array}{c}\text { Hyperventilation - effort to compensate for } \\
\text { the oxygen deficiency. Impaired coordination } \\
\text { of muscle movements. }\end{array}$ \\
\hline 12 & Headache, rapid tiredness, dizziness. \\
\hline 9 & Unconsciousness. \\
\hline 6 & Death (after a few minutes). Asphyxia \\
and heart failure.
\end{tabular}

A conflagration also produces a wide range of toxic substances. Their properties and their quantity depend on the original properties of the combustible matter. A variety of substances with different properties is produced naturally as well as industrially. During a fire, these substances react and, as a result, hundreds of new substances with new, and in most cases, more dangerous properties are created. Moreover, even firefighting can encourage creation of toxic substances.

\footnotetext{
* Martin Hrinko ${ }^{1}$, Katerina Orlikova ${ }^{2}$

${ }^{1}$ Regional Directorate of the Moravian-Silesian Region, Czech Republic, E-mail: martin.hrinko@seznam.cz

${ }^{2}$ Judicial expert in the field of chemistry - combustion and chemical explosions, Sokolovska 1178, Ostrava - Poruba, Czech Republic
} 
2. Conflagration and the resulting toxicants in dependence on the course of the fire and the nature of the combustible matter $[4,5]$

This chapter describes the origin, properties and the influence of those toxicants, which are most frequently produced during a conflagration. More specifically, the chapter describes the toxicity of the following compounds:

- carbon compounds (namely carbon dioxide, carbon monoxide and various hydrocarbons contained in the table of toxicity),

- sulphur compounds (namely carbon disulphide, hydrogen sulphide and sulphur dioxide),

- nitrogen compounds (namely nitrogen oxides, ammonia, cyanide compounds and amines) and

- phosphorus compounds (the chapter describes the properties of phosphorus oxides).

A table describing the immediate lethal doses of each of the toxicants most frequently produced by conflagration represents an important part of this chapter. As it has already been stated, during a fire, numerous new compounds are created (as the intermediate products or as the end products of combustion). The intermediate products are, for example, high-molecular hydrocarbons (often aromatic or polyaromatic hydrocarbons) in the form of an oxygen compound (such as aldehydes, ketones, esters, high-molecular alcohols, etc.). Some nitrogen compounds which can be included in combustion products are cyanide compounds, various types of highly toxic amines, nitrogen oxides or ammonia. The oxides of combustible elements (contained in a combustible matter) are the end products of combustion. Most often, these are oxides of carbon, sulphur, phosphorus and other chemical elements. Their toxic properties can be found in the the following text as well as in the table below.

\subsection{Toxic properties of carbon compounds produced by a fire}

The carbon compounds produced by a fire are carbon dioxide $\mathrm{CO}_{2}$, carbon monoxide $\mathrm{CO}$ and, depending on the type of the fire and its temperature, hydrocarbons (such as carbon disulphide $\mathrm{CS}_{2}$ - a combustible and an explosive substance).

Carbon dioxide $\mathrm{CO}_{2}$ - is a product of a complete combustion of carbonaceous matters. It is a colourless gas with a slight acidic odor, which irritates the pituitary membrane. It is easily liquefiable and at $1 \mathrm{~atm}$ it changes to a solid commonly called "dry ice" or "dry snow". Dry ice has the temperature of $-78.48^{\circ} \mathrm{C}$ and if it comes into a direct contact with skin, it causes serious burns. Carbon dioxide is heavier than the air. The weight of 1 litre of $\mathrm{CO}_{2}$ is $1.97 \mathrm{~g}$ (at $1 \mathrm{~atm}$ and $0{ }^{\circ} \mathrm{C}$ ). Its density in relation to the density of the air is 1.52. Therefore, it accumulates near the floor, in basements, pits, wells, etc. It dissolves in water. The dissolution is accompanied by formation of carbonic acid, which has corrosive effects. Carbon dioxide is non-flammable, but will support the combustion of metals. It reacts with metals, forming flammable, explosive and highly toxic carbon monoxide: for example:

$$
\mathrm{Mg}+\mathrm{CO}_{2}=\mathrm{MgO}+\mathrm{CO}
$$

Carbon dioxide also reacts with carbon (a non-metallic element):

$$
\mathrm{C}+\mathrm{CO}_{2}=2 \mathrm{CO}
$$

The chemical equilibrium in the reaction above depends on the temperature of the fire and on an eventual presence of catalysts. Carbon dioxide is not a toxic gas (it does not alter cellular functions), but it is unbreathable. It is an end product of metabolism of organisms. As for human beings, the alveolar air contains 5-6\% of $\mathrm{CO}_{2}$, the exhaled air contains approximately $3.5 \%$ of $\mathrm{CO}_{2}$. If inhaled, its irritating effects are negligible, except for its principal effect, which is difficulty in breathing and shortness of breath or even death. A human body is able to adapt only to a low concentration of $\mathrm{CO}_{2}$ in the air. However, a long exposure to such air has subnarcotic effects. Human body is able to adapt to the concentration of $\mathrm{CO}_{2}$ in the air equal to $2 \%$. This concentration causes deeper breath and, as a result, other toxic substances produced by fire easily enter the human body and may cause death. A $5 \%$ concentration of $\mathrm{CO}_{2}$ in the air provokes difficulty in breathing, vomiting, increased blood pressure, disorientation and, after prolonged exposure, loss of consciousness. A $7 \%-10 \%$ concentration of $\mathrm{CO}_{2}$ in the air causes loss of consciousness and rapid death. Human beings have different levels of sensitivity to carbon dioxide.

Carbon monoxide $\mathrm{CO}$ is the product of an incomplete combustion of carbon. It is a colourless and odorless gas. It is highly toxic, combustible and is explosive in a mixture containing oxygen. Carbon monoxide is a part of many industrial gases (such as blastfurnace gas, coke oven gas, producer gas, exhaust gases etc.). The weight of 1 litre of $\mathrm{CO}$ is $1.25 \mathrm{~g}$ (at $1 \mathrm{~atm}$ and $0{ }^{\circ} \mathrm{C}$ ). Its density in relation to the density of the air is equal to 0.96 , which means that carbon monoxide is slightly lighter in comparison with the atmospheric air. In the presence of oxygen, carbon monoxide burns at temperatures lower than $700{ }^{\circ} \mathrm{C}$, producing carbon dioxide. Carbon monoxide is a highly toxic gas. Carbon monoxide has a high affinity to hemoglobin. It combines with hemoglobin to produce carboxyhemoglobin. As a result, the human body suffers from a lack of oxygen and dies of asphyxia. The lethal concentration of $\mathrm{CO}$ in the air is $4,000 \mathrm{ppm}(0.4 \%$ of the air). The presence of any other toxicants increases its effects. Besides its principal effect, this gas also affects the nervous system, digestive system, endocrine glands, blood serum and the organs of hearing and vision. Due to the prevalence of $\mathrm{CO}$ in industrial gases, it causes approximately $50 \%$ of all industrial poisonings. As it also often occurs in enclosed places, it causes explosions.

Hydrocarbons are produced as intermediate products during a fire. They are combustible, often explosive and toxic. Hydrocarbons are a large group of compounds consisting of hydrogen and carbon. They are used in many industrial branches. Hydrocarbons may be formed naturally as well as industrially in all three common states of matter. At high temperatures and during a fire, they occur frequently in the gaseous state. Hydrocarbons serve as a raw mate- 
An overview of toxicity rates of the chosen hydrocarbons. [2]

Table 2.

\begin{tabular}{|c|c|c|}
\hline Class & Danger level & Examples \\
\hline O & Substance presenting no danger & Water, nitrogen, oxygen, helium, sodium chloride \\
\hline A & Substance presenting a very low danger & Methane, carbon dioxide, ethanol \\
\hline B & Slightly dangerous substance & Phosphoric acid, oxirane, ammonia \\
\hline C & Moderately dangerous substance & Sulphur dioxide, nitrobenzene \\
\hline D & Highly dangerous substance & Carbon monoxide, chlorine, potassium cyanide \\
\hline E & Severely dangerous substance & Hydrogen sulphide, phosgene, hydrogen cyanide \\
\hline F & Extremely dangerous substance & Tabun, nickel tetracarbonyl, tetraethyl phosphate \\
\hline
\end{tabular}

rial used in chemical industry. They are also used as fuels and solvents for pharmaceutical and cosmetic production, etc. The acute toxic effects of hydrocarbons affect the nervous system. Their effects are mostly narcotic and depressive. In a homologous series, the narcotic effect increases with the higher number of carbon atoms in a molecule. Alkanes and alkenes which have the same number of carbon atoms have the same narcotic effects. The effects of alkadienes, alkynes and cycloalkanes are stronger. The excitation effect of hydrocarbons is also very dangerous (especially for the firefighters) - it causes irritation or convulsions. Carcinogenic and mutagenic properties of aromatic and polyaromatic hydrocarbons do not occur during a fire. They strongly affect human health a few hours later. The immediate effects of hydrocarbons during a fire are irritation of the airways, eyes and skin. All types of hydrocarbons preferentially damage liver, kidneys, myocardium and blood vessels. The Toxicology and Chemical Substances code system (TCS) [2] classifies the particular substances according to their danger level in the following Table No. 2. The first capital letter in the table defines the rate of acute toxicity, the next letter in the table defines the rate of chronic toxicity. In case of a short exposure to fire (one work shift) the acute toxicity represents a bigger threat. In case of a prolonged exposure (several work shifts spent firefighting) chronic toxicity may appear. Some examples of toxicity rates of different substances can be seen in Table 2 .

\subsection{Toxic properties of chosen sulphurous compounds produced by a fire $[2,5]$}

If a combustible matter contains sulphur in its molecule, carbon disulphide $\mathrm{CS}_{2}$ may be an intermediate product of the combustion. This chemical compound is often used in chemical industry as a raw material or it is produced as an intermediate product and, in case of an emergency, it leaks into the air.

Carbon disuphide is a colourless, low-boiling liquid. Its vapours are highly flammable and it burns according to the following equation:

$$
\mathrm{CS}_{2}+3 \mathrm{O}_{2}=\mathrm{CO}_{2}+2 \mathrm{SO}_{2}
$$

In its pure form, carbon disulphide is aromatic; if produced industrially, it smells unpleasantly. It enters the human body through the airways or skin. The acute intoxication provokes incoordination, dizziness, delirium and hallucination. Later, it causes loss of consciousness or even death from respiratory paralysis. Chronic intoxication by carbon disulphide causes mental defects: excitement and depression. The intoxication also causes hypotension. The lethal dose of carbon disulphide is $5,000 \mathrm{ppm}(0.5 \%$ of the volume of the air).

The end product of combustion of sulphur compounds is sulphur dioxide $\mathrm{SO}_{2}$, a colourless gas with a pungent odor. It is heavier than the air (its density in relation to the density of the air is 2.2). It dissolves well in water and the resulting solution is called sulphurous acid. This solution has reduction properties and causes corrosion of metal structures or equipment. In the form of acid rains, it affects the $\mathrm{pH}$ of soils and vegetation. Sulphur dioxide is a toxic gas and has a negative influence on plants and animals. It causes the dying out of leaves of plants, their whitening and browning. The major influence of $\mathrm{SO}_{2}$ on an adult is its irritating effect. It irritates moist mucous membranes (e.g. eyes, nose, mouth, but also skin), particularly the upper respiratory tract. A small acute toxication causes bronchitis and conjunctivitis. Longer exposure to sulphur dioxide (e.g. $500 \mathrm{ppm}$ ) causes apneusis, glottidospasm and, consequently, death.

Hydrogen sulphide $\mathrm{H}_{2} \mathrm{~S}$ is a gas with the characteristic odor of rotten eggs. It is slightly heavier than the air, it is soluble in water and forms an acidic solution. It is toxic and often causes serious intoxication. After it enters a human body, it reacts with many important enzymes and, therefore, it influences life functions. It has a negative influence on the central nervous system, which results in respiratory paralysis. It has irritating effects. The course of an acute intoxication may be very quick, especially during firefighting.

The symptoms of intoxication are:

- loss of consciousness,

- apneusis,

- cardiac arrest.

Even after the healing process visual, liver and kidney impairment persist. Besides the fact that hydrogen sulphide enters the body through respiratory organs, it is also absorbed through skin. It has good warning properties, because its smell can be detected 
from a concentration of $0.3 \mathrm{ppm}$. Concentrations above $200 \mathrm{ppm}$ cause impaired olfaction, a concentration of $600 \mathrm{ppm}$ is lethal.

\subsection{Toxic properties of chosen nitrogen compounds produced by a fire}

Nitrogen compounds are often produced by a fire. They are products of combustion of natural flammable matters (such as wool, cotton, etc.) as well as of synthetic flammable matters (such as synthetic fibres, foamed or classic forms of plastic, etc.). The aforenamed matters are widely used in industry and engineering, in households as well as in social facilities. Other synthetic products of daily use which produce nitrogen compounds when burning are for example carpets, curtains, sofas and their covering and padding, etc. Combustive matters containing nitrogen atom in their molecules produce a wide range of inorganic and organic toxic products Most frequently, these are: nitrogen oxides, ammonia, cyanide compounds and amines. At high temperatures nitrogen combines with oxygen to produce nitrogen monoxide NO.

Nitrogen monoxide $N O$ is a colourless gas. It is volatile when exposed to the air. It quickly combines with oxygen to form nitrogen dioxide $\mathrm{NO}_{2}$. In toxicology, the effects of nitrogen monoxide and nitrogen dioxide are summarized under a generic term "oxides of nitrogen" $\mathrm{NO}_{\mathrm{x}}$. Nitrogen monoxide has a negative influence on the central nervous system. It reacts with blood, specifically with hemoglobin, to form nitrosyl hemoglobin. In toxicology, nitrogen monoxide is considered to be a less toxic product of fire than nitrogen dioxide $\mathrm{NO}_{2} \cdot \mathrm{NO}_{2}$ is a highly toxic oxide of nitrogen.

Nitrogen dioxide $\mathrm{NO}_{2}$ is a reddish-brown liquid. At temperatures above $21{ }^{\circ} \mathrm{C}$, it turns into a reddish-brown smoke. During a fire it occurs as a dimer $\mathrm{N}_{2} \mathrm{O}_{4}$ and its main toxic effect is irritation. Its harmful effects depend on its concentration and the length of exposure. At the concentration of only $35 \mathrm{ppm}$ of $\mathrm{NO}_{2}$ in the air the length of exposure should not exceed 5 minutes. Its immediate lethal concentration is $300 \mathrm{ppm}$. In case of intoxication by $\mathrm{NO}_{2}$, there exists a so-called latent period (i.e. the time period between the inhalation of $\mathrm{NO}_{2}$ and the appearance of the first symptoms of intoxication). After inhalation of $\mathrm{NO}_{2}$ the intoxicated person may feel relatively well. However, the symptoms of intoxication appear 5 to 72 hours later.

\section{The symptoms of intoxication are:}

- decrease in blood pressure,

- inspissated blood,

- difficulty in breathing,

- pulmonary edema

- apneusis,

- death.

The chronic effects of $\mathrm{NO}_{2}$ include conjunctivitis, bronchitis and dental impairment. Longer exposure to $\mathrm{NO}_{2}$ decreases immunity. Recently, a research has shown that $\mathrm{NO}_{2}$ may even have carcinogenic effects. Another product of combustion and another cause of frequent industrial and transport accidents is ammonia $\mathrm{NH}_{3}$.
Ammonia $\mathrm{NH}_{3}$ is a colourless toxic gas with a choking odor. It is explosive and flammable when mixed with oxygen. Ammonia burns in oxygen with a yellow flame to produce nitrogen and water:

$4 \mathrm{NH}_{3}+3 \mathrm{O}_{2}=\mathbf{2} \mathrm{N}_{2}+6 \mathrm{H}_{2} \mathrm{O}$

Although ammonia is a toxic substance, it is easily recognizable - its pungent odor is recognizable at a concentration of $5 \mathrm{ppm}$. Due to its good solubility in water, it often irritates mucous membranes, eyes and the upper respiratory tract,

- it affects cornea and may cause corneal opacity,

- it irritates the central nervous system,

- it provokes convulsions,

- it causes hearing impairment and kidney impairment.

At a concentration of $5,000 \mathrm{ppm}(0.5 \%$ of the air $)$, it causes rapid death. At concentrations above $10,000 \mathrm{ppm}$, it damages skin and affects the airways even if they are well-protected. A conflagration of a natural as well as synthetic combustible matter containing nitrogen in its molecules produces a wide range of cyanide compounds and amines. Both of these groups are highly toxic.

Hydrogen cyanide $H C N$ is a colourless liquid with a bitter almond-like odor. Hydrogen cyanide boils at $26.5^{\circ} \mathrm{C}$. During a fire it occurs in the gaseous state. It is highly toxic. It dissolves well in water and in the solution it dissociates according to the following equation:

$$
\mathrm{HCN} \rightleftarrows \mathrm{H}^{+}+\mathrm{CN}^{-}
$$

The cyanide anion halts cellular respiration. A lethal dose of hydrogen cyanide for an adult is $0.04-0.06 \mathrm{~g}$. This dose causes convulsions and rapid death. Some of the most common organic cyanide compounds are potassium cyanide $\mathrm{KCN}$ and sodium cyanide $\mathrm{NaCN}$. They have typical cyanide effects, but their toxicity is slightly lower than that of HCN. Their lethal dose for an adult is $0.2-0.3 \mathrm{~g}$.

Plastic materials have become an integral part of our everyday life. The macromolecules which form these materials and, consequently, the products made of plastic are not toxic. When burning, the macromolecules dissolve to produce the original molecules. That way, amines are often produced by a fire. Amines are organic compounds which are highly toxic. Their acute toxicity is similar to that of cyanide compounds; their chronic toxicity is even higher and amines are usually assigned the highest toxicity rate in the toxicology code system. However, the cases of amine poisoning are not very common, as amines are easily distinguishable due to their pungent smell at low concentrations.

\subsection{Toxic properties of phosphorus compounds produced by a fire}

If contained in a combustible matter, phosphorus usually burns to produce its oxides (phosphorus trioxide $\mathrm{P}_{2} \mathrm{O}_{3}$ and phosphorus pentoxide $\mathrm{P}_{2} \mathrm{O}_{5}$ ). Both of these substances are solid (at $1 \mathrm{~atm}$ and 
$0{ }^{\circ} \mathrm{C}$ ). When burning, they form dimers (phosphorus trioxide forms $\mathrm{P}_{4} \mathrm{O}_{6}$ and phosphorus pentoxide forms $\mathrm{P}_{4} \mathrm{O}_{10}$ ). Both of these oxides turn into the gaseous state during a fire.

Phosphorus trioxide P2O3 is obtained by the combustion of phosphorus in a limited supply of oxygen. Even at low temperatures, it combines with oxygen to form oxide of phosphorus. It is toxic and its acute effects are severely dangerous. It dissolves in cold water to form phosphorous acid $\mathrm{H}_{3} \mathrm{PO}_{3}$. The hot water dissolves both the oxide and the acid to form phosphane $\mathrm{PH}_{3}$, which is, again, highly toxic. An intoxication by phosphorus compounds containing phosphorus with an oxidation number equal to 3 (PIII) affects the whole human body. The symptoms of intoxication are difficulty in breathing, stomach ache, decrease in blood pressure, nervous disorder and jaundice.

Phosphorus pentoxide $\mathbf{P}_{2} \mathbf{O}_{5}$ is obtained by a complete combustion of phosphorus. When exposed to the air, it gets wet and turns into a syrup. It is very hygroscopic and combines with water. This reaction is accompanied by a hissing sound. It is less toxic than $\mathrm{P}_{2} \mathrm{O}_{3}$ and its acute effects are only moderately dangerous (it provokes an irritating cough). Phosphorus pentoxide becomes dangerous when polluted by white phosphorus, which is classified as a severely dangerous substance.

\section{Plastics in fire from a professional experience [7]}

Fire in the Remiva plastic-recycling plant and storehouse in Chropyně, the Czech Republic, broke out at about 1 a.m. on Friday, 8th April 2011. At that time only a few night-shift workers were present in the factory. They all managed to escape from the site. The fire spread as far as $250 \mathrm{~m}$ from the focus during the night. The firefighting was inefficient as a strong wind was blowing and it was impossible to locate the fire. A helicopter was used to extinguish the fire from above. The fire produced a thick black smoke until Sunday evening. Even on Monday, when the firefighters extinguished all the centres of the fire, there was still smoke above the site. A powerful odor from the fire filled the air in the neighbouring area and due to intense firefighting, the local sewage treatment plant was unable to hold the excessive amounts of water. A change in winds made the firefighting even more complicated, as it carried the smoke to the town centre and to the nearby residential area. An irritating plume of smoke was rising from the burn-out area. The firefighters were measuring the concentration of toxicants in the air and forwarding the data to the headquarters and the officer in charge. The measurement of the concentration of toxicants showed that toxic substances were being emitted to the air. Due to their high concentration in the air, the officer in charge ordered an evacuation of the adjacent streets. Administrative authorities suggested an evacuation of approximately 300 people living in the area which was affected by the smoke. The firefighting was moreover complicated by a lack of water supply, because the fire also spread to a building containing water pumps. This made the use of hydrants impossible. The firefighters then had to organise shuttle traffic which carried water from a small lake. On Saturday morning, parts of the burn-out buildings collapsed, which caused an explo- sion of hot gases. On Saturday evening, the firefighters managed to extinguish the fire on two-thirds of the afflicted area. On Sunday, the experts of a fire rescue unit from Hlučin arrived to help with their heavy equipment. Without their participation it would have been impossible to access the largest focus which was hidden under the ruins. The firefighters managed to knock down one of the large walls and one of the factory buildings using heavy chains and the Tatra 815 vehicle. The experts from Hlučín finally accessed the last centre of the fire through the perforated ruins shortly before 5 p.m. The last centre of the fire, which resisted firefighting for three days, was consequently showered with water and low expansion foam. On the third day of the fire, the firefighters accessed the last large focus, which was the most dangerous of all. Water tanks, engines and aerial appliances dispersed large volumes of water and low expansion foam on the last few small hidden centres of the fire. After the fire had been located, the officer in charge cancelled the evacuation at 5 p.m. on Sunday afternoon and, after two days, the inhabitants returned to their homes. The site was fenced in order to prevent unauthorised persons from entering it and to preserve the evidence needed for further investigation of the causes of the fire. Firefighters from 67 professional, voluntary and corporate units from 4 regions of the Czech Republic rotated in the place trying to extinguish the fire. It was the most extensive fire in the history of the Moravian-Silesian Region. The owner of the company has not assessed the loss yet, but the first estimations state that the loss is tens of millions of Czech crowns. No lives were lost in the fire. Only two volunteer firefighters were injured. The company lost approximately 1500 tonnes of plastic materials because of the fire. According to the night-shift workers and the manager of the production, the first flames occurred on the roof of the factory building. However, it is difficult to establish where exactly the fire broke out. The investigation of the possible causes of the fire has only just begun.

\section{Conclusion}

Nowadays, plastic materials have become an indespensable part of our lives. Products made of plastic are used in building

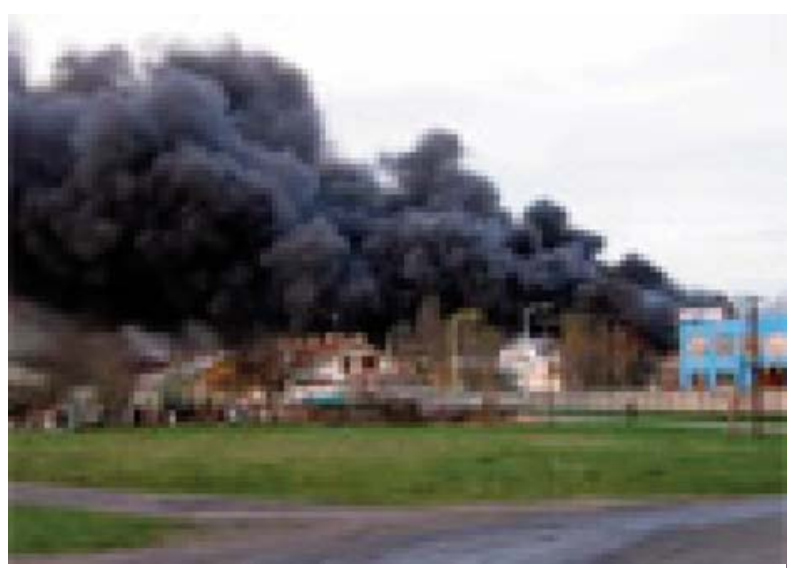

Fig. 1 Fire in the manufacturing and logistics premises in Chropyne [7] 
industry, transportation, mechanical engineering, in car, pharmaceutical and in many other industries; even our households are full of plastic products. The use of these materials has many advantages and disadvantages. The disadvantages are that the plastic materials are mostly flammable, they burn at high temperatures and they produce a wide range of dangerous and highly toxic substances. It is easier to extinguish a fire in a flat or in a house than in a factory building used for the production and storage of flammable materials (e.g. plastics). Therefore, it is utterly important to strictly maintain production process and workplace safety regula- tions. Fortunately, in the fire in the plastic-recycling plant in Chropyně no lives were lost. However, it is vital to remember that such fires have caused great property losses and killed many people worldwide. At present, the investigation of the Chropyně case has not been closed. Judging from the chemical composition of the burnt material, the fire produced many toxic substances in the form of intermediate and end products. Owing to favourable wind direction and dispersion, the toxicants from the smoke did not affect the health of the inhabitants.

\section{References}

[1] ORLIKOVA, K.: Organic Chemistry for Coal-miners and Metallurgists, Parts I, II and III, Ostrava : Study materials of VSB-Technical University of Ostrava, 1992.

[2] MARHOLD, J.: An Overview of Industrial Toxicology, Inorganic Compounds, Pratur : Avicenum, Czech Republic 1980.

[3] MARHOLD, J.: An Overview of Industrial Toxicology, Organic Compounds, Pratur : Avicenum, Czech Republic 1986.

[4] ORLIKOVA, K.: Chemistry of Combustible Matters and Products of Combustion, Ostrava : Study materials of VSB-Technical University of Ostrava, 1991.

[5] HRINKO, M.: Fire as a Producer of Toxic Substance, Ostrava : Master thesis, Faculty of Mining and Geology, VSB-Technical University of Ostrava, p. 53, Czech Republic, 2002.

[6] ORLIKOVA, K., HRINKO, M.: The Impact of Different Extinguishing Agents on the Chemical Composition and the amount of Toxicants Produced During a Fire, Professional journal about fire protection, rescue system and protection of people "112“, Prague : Ministry of Interior - General Directorate of Fire Rescue Service of the Czech republic, Czech Republic, 2004, No. 1, ISSN 1213-7057

[7] WWW: Mediafax: Experts from Hlucin Extinguish the Fire in Chropyne Using Heavy Equipment. Several walls were knocked down, [date accessed: 10.4.2011], Prague : http://zlin.cz/upload/7/70b12ad4_b_0_pozar_chropyne_3_b.jpg, 2011.

[8] POLEDNAK, P., SVETLIK, J.: Large - Scale Fire Tests of Passenger Cars, Ostrava: Int'n. conference of Fire Safety, 2010, SPBI Ostrava, pp. 303, ISBN: 978-80-7385-087-6, ISSN: 1803-1803.

[9] KEBO, V., STRAKOS, V.: The Utilization of Virtual Reality in the Control of Objects and Technology, Proc. of Int'n. Symposium on Earth Science and Technology 2009, CINEST, 2009, pp. 221-226. 978-4-9902356-0-4. 